ciliary injection, shallow anterior chamber, steamy cornea, $\mathrm{T}+2$, ripe cataractous lens, with good p.l. and projection. After one day in hospital, during which leeches, salines, and eserin were used, operation was performed under chloroform; cocain and adrenalin in the eye. The section was sclero-corneal with a large conjunctival flap, iridectomy-dialysis, extraction with irrigation of anterior chamber with saline solution. Removal of some blood clots from the anterior chamber with iris forceps was followed by prolapse of vitreous.

The same evening, about six hours later, the dressings were found soaked with blood and the patient complained of severe pain in his eye. The bandage was removed and the wound found to be bulging. The conjunctival sac was full of blood clots which were removed. Both eyes were bandaged and morphia was administered.

The next day the dressings were soaked with blood and for about a week the wound bulged and serum oozed out of it. The pain gradually lessened. The wound had almost healed by July 19 and the pupil was occluded. He left hospital on the July 21 and attended the out-door regularly. He suffered from iritis for about a month. No pain after the end of October and no ciliary injection.

On December 29 iridotomy was performed under cocain, by a very ground-down fine Graefe's knife-cutting horizontally through the iris. He did well, and on January 25,1917 , with a +11.0 lens saw 5/40 (dots). Seen again on March 6, the same lens gave him $3 \cdot 5 / 15$, and with +16.00 he could see the eye of a needle at 12 inches. The fundus was seen badly, but appeared normal. There was incipient cataract in the other eye.

\title{
A NOTE ON THE AETIOLOGY OF SYMPATHETIC OPHTHALMITIS
}

\author{
BY \\ C. G. RUSS Wood, F.R.C.S. \\ SHREWSBURY.
}

NUMEROUS observers have remarked on the similarity between the microscopical characters found in sympathic ophthalmitis and those in tuberculous infections of the eye; indeed, Meller has suggested that the micro-organism causing sympathetic disease is already present in the blood at the time of the injury. Many cases of tuberculous disease of the eye have clinical appearances (such as fine "keratitis punctata," etc.), which are very similar to the early stages of sympathetic ocular infections. 
The following two cases have been under my care during the last two years :

Case 1.-R. J., aged 25 years. Struck in the left eye with a piece of cast iron, November 1, 1916. There was a wound of the cornea with prolapse of the iris. He was seen five days after the injury and an iridectomy performed at once; the iris was partly caught in the wound. On November 16 the vision was R. 6/6; L. 6/12. He left the hospital with the left eye perfectly quiet, but returned on December 23 with well-marked sympathetic disease in the right eye. He was given two doses of salvarsan with apparently no benefit. On January 11 he was given 0.0001 of T.O. Two days later there was a marked focal reaction in the sympathizing eye which lasted for five days. There was no reaction in the injured eye, which became distinctly quieter during this time. The same dose of tuberculin was repeated on February 18 with no reaction. It was again repeated on March 1, and was followed by a most intense reaction in the sympathizing eye accompanied by increased tension. There was no change to be observed in the injured eye.

Case 2.-L. M., aged 12 years. Wound of the right cornea with an arrow on May 3, 1915. The eye quieted down and the child ceased attending the hospital, but appeared on September 8, 1915, with well-marked serous sympathetic ophthalmitis. T.O. $0^{\circ} 0001$ was given on September 29, which was followed in two days by a marked focal reaction in the sympathizing eye. No reaction in the injured eye. This was repeated on October 8, followed by a doubtful reaction two days later. The dose was again repeated on November 28, and followed by another doubtful reaction in the sympathizing eye.

In neither of these cases was the exhibition of tuberculin followed by any apparent benefit. The first patient was a very severe infection, and the vision is now in each eye about fingers at six inches. The second patient was a much less severe infection, and the present vision is now 6/36 in each eye. In neither of the patients are the eyes at all quiet up to the present time.

Both of these patients had injections of salvarsan with apparently no benefit. It should also be noted that no observable improvement as regards vision took place after the tuberculin injections, but a steady deterioration. This may be due to their not having been repeated often enough; but, unfortunately, one often sees the same result in ordinary tuberculous eye infections, where a reaction takes place and the eye eventually quiets down, but no improvement of the vision takes place.

Assuming these observations to be correct, how can the above specific reactions be explained? It seems a feasible hypothesis to suggest that the phenomenon of symbiosis may be concerned in the 
condition. Symbiosis is the co-habitation of two different organisms for their mutual benefit, as, for example, the increase in virulence of diphtheria bacilli in the presence of streptococci. It has been noted that symbiosis frequently occurs between amoebae and bacilli, therefore as the blood changes in sympathetic disease are similar to those found in protozoal infections, it is tempting to suggest that sympathetic ophthalmitis is due to symbiosis between the tubercle bacillus and some unknown protozoon.

Neither of these patients showed any signs of tubercle elsewhere in the body, and I do not suggest that the wound was infected with tubercle at the time of the accident. It seems more likely that the eye was affected at the time of the accident by some organism which in the presence of the tubercle bacillus is capable of producing the disease we know as sympathetic ophthalmitis. Against a tuberculous infection at the time of the accident is the fact that only the sympathizing eye showed any reaction to the tuberculin injections.

\section{Report of the Departmental Committee on the Welfare of the}

Blind. Published by His Majesty's Stationery Office, London, 1917.

This Committee was appointed on May 7, 1914, "to consider the present condition of the blind in the United Kingdom, and the means available for $(a)$ their industrial or professional training, and (b) their assistance, and to make recommendations."

The Rt. Hon. W. Hayes Fisher (now President of the Local Government Board) was appointed Chairman; the Committee originally consisted of 12 members, but the number was subsequently increased by the addition of three names. The only lady member of the Committee (Mrs. Alice Westlake) was prevented by ill-health from taking any active share in the proceedings.

The Committee held 38 meetings and examined 53 witnesses. Ten sittings had been held when war broke out. The Committee then adjourned but met again on March 18, 1915, and decided to resume their sittings.

The Report, which extends to 71 pages, contains the following 12 sections :-

I. Report of the Royal Commission, 1889.

II. Scope of the Problem.

III. Age of Incidence and Causes.

IV. Elementary Education of the Blind.

V. Professional Training. 
VI. Industrial Training.

VII. Workshops.

VIII. Miscellaneous Organizations.

IX. The Poor Law.

$\mathrm{X}$. The Incapable.

XI. Pensions.

XII. Blinded Soldiers and Sailors.

Under each of the headings will be found information, often given with a good deal of detail, which is of interest in reference to existing conditions, and of great importance in relation to the decisions of the Committee. The "General Conclusions and Summary of Recommendations" follow Section XII. It is this part of the Report to which most readers will turn and which will attract most attention; from it the subjoined excerpts are taken.

The "Conclusions" are signed by all the members of the Committee; there are, however, seven reservations under the signatures of seven members (most of these reservations are signed by more than one), the tenor of which is not antagonistic to the recommendations generally.

Added to the Report are three appendices: (1) the names of witnesses examined ; (2) a list of Institutions, Societies and Charities for the Blind in the United Kingdom ; (3) the Report, prepared at the request of the Committee, by the Council of the Section of Ophthalmology of the Royal Society of Medicine.

\section{General Conclusions and Recommendations}

(1) Central Control.-The Committee find that the recommendations of the Royal Commission of 1889 have been largely neglected, and they have "come clearly to the conclusion" that the condition of the blind calls for more active intervention of the State to secure (a) central control, organization and assistance for the existing agencies of voluntary help which could be better utilized if centrally directed, and (b) additional assistance for the blind."

The Committee therefore recommend that a Special Department, whose function shall be the general care and supervision of the blind, shall be set up, in the Ministry of Health (when created) and in the meantime in the Local Government Board. This special department should have at its disposal funds provided by the Exchequer. It should be under the immediate guidance of a strong Advisory Committee of persons associated with the care of the blind. This special department with the advisory committee is referred to in the recommendations as the "Central Authority."

The initial capital expenditure which is most essential is that required for increasing the workshop accommodation for the blind. Some 3,000 additional places are urgently required; the sum necessary for the provision of these is estimated at $£ 500,000$. The 
annual requirements of the Special Department are estimated at $£ 250,000$.

Definition.-The Committee think it desirable that a uniform definition of blindness should be adopted in the case of adults, viz.: "Blindness means too blind to perform work for which eyesight is essential." This is the definition proposed by the Council of the Section of Ophthalmology of the Royal Society of Medicine.

The Committee think " that certain safeguards should be adopted in applying this definition, viz.:-That the examination of the blind should be made by registered Medical Practitioners who possess competent knowledge of the diseases of the eye, and that a certificate should be given indicating if the case should be re-examined."

Causes of Blindness and Age of Incidence.-The Committee accept the conclusion that ophthalmia neonatorum is responsible for over 10 per cent. of the cases, and are satisfied that blindness resulting from this cause can be materially reduced if notification is accompanied by immediate treatment. They are also convinced that the proportion of blindness caused by accident could be reduced if the wearing of protective glasses were more generally enforced in dangerous occupations. They recommend that:-

(a) Steps should be taken to assure uniform and more eftectual notification of ophthalmia neonatorum.

(b) The careful attention of the authorities should be drawn to the representations which have been placed before the Committee that the instructions to midwives should be amended so as to provide more ample protection against this disease.

(c) Arrangements should be made to secure immediate treatment of all cases, such as is provided in certain towns at the present time. Local authorities should be urged to avail themselves of the grants payable under the Maternity and Infant Welfare Scheme. Hospital accommodation should be provided wherever it is deficient.

(d) Ophthalmia neonatorum should be made compulsorily notifiable in Scotland.

(e) The provision and wearing of goggles in dangerous occupations should be made more widely obligatory than it is at present.

(f) More precise statistics should be kept of the amount of blindness due to mechanical injury.

Elementary Education. - The provision for elementary education in England, Wales and Scotland may be regarded as generally satisfactory; but the Committee are impressed with the desirability of establishing a system of public elementary education in Ireland; and of increasing generally the provision for the education of myopic children. They emphasize the necessity of initiating a general system of after-care by establishing a register of all blind children 
in the public elementary schools, and are convinced that the systematic following up of blind children is a fundamental essential to the proper care of the blind. They make a series of cogent and carefully considered recommendations in reference to these questions.

Professional Training.-The Committee are satisfied from the evidence obtained that there are some professions on which blind persons may embark with a reasonable prospect of success. The present accommodation for professional training appears to be generally adequate, but better organization in the distribution of the funds available seems necessary. Among other recommendations the Committee suggest that the Government should consider the desirability of increasing the facilities for the higher education and professional training of blind persons and of extending the grants payable in respect of pupils undergoing professional training; and the Central Authority should endeavour to secure financial assistance for persons embarking on professional careers.

They draw attention to the precarious financial position of the Royal Normal College for the Blind.

Industrial Training.-The accommodation for industrial training does not appear to be materially deficient. At present in England many more persons receive industrial training than can be afterwards employed in the available workshops.

In Scotland a number do not receive training because workshop accommodation is not available for their subsequent employment. The financial position of institutions at present providing industrial training for the blind is unsatisfactory, the training costing between $£ 6$ and $£ 10$ per head per annum over and above the sums found by the rates and taxes. The result is that the majority of such institutions are dependent upon constant appeals to public charity.

The Committee find that the period of training required may be taken on the average as four years after the age of 16 , and that the age limit within which training may begin with advantage is probably 50 years. They think that special arrangements should be made to secure grants for persons becoming blind in later life, who are frequently reduced to serious straits during the period of training. The training institutions should be in close touch with the workshops in order that the methods of training may be based upon the actual methods in operation in the workshops. Blind instructors might be more generally employed in industrial training.

Workshops.-The Committee are satisfied that the crux of the problem of the blind in the United Kingdom at the present moment is the inadequacy of workshop accommodation. The recommendations of the Committee under this heading are of special importance. They are briefly :--

The existing accommodation should be at least doubled ; Government should provide funds for this purpose. 
The Central Authority should make arrangements with the spending departments of the Government to secure that in certain contracts blind institutions are given the preference. Steps should also be taken to eliminate the unnecessary competition between existing institutions by securing the amalgamation of small workshops to larger institutions, and special attention should be given to the amalgamation of workshops in London. Efiorts should be made to ensure that persons working at home should be assisted in the purchase of materials and the marketing of their goods. Particular attention should be directed to the employment of blind women.

Miscellaneous Organizations.-Much excellent work is done by these societies, but the Committee are satisfied that the blind could be helped to a far greater extent if the operations of the various organizations were controlled and assisted by some central body.

The Committee recommend that one of the duties of the Central Authority should be to co-ordinate the efforts of the various organizations which care for the blind outside institutions. The organization in Scotland is already highly efficient, but financial assistance may be necessary. The organizations of the English Unions should be completed as rapidly as possible, and Government assistance is required for this. The Central Authority should enquire into the position of the home teaching societies and the Unions generally in order to secure more scientific collaboration between them.

The Committee are emphatic in their recommendation concerning the provision of books for the blind. Since they obtained evidence on this point, the National Library for the Blind has been made free to every blind person; the Committee recognize the urgent need for a central free library and in order to ensure the continuation and development of this organization, they recommend a State subsidy either by way of capital or of annual grant. They also urge that administrative measures should be taken to secure the active co-operation of the Home Teaching Societies and Public Libraries with the National Library for the Blind so as to facilitate the circulation and distribution of the books available and to minimize still further the danger of unnecessary duplication in production. They consider it necessary that the supply of Moontype books should be increased, and that the efforts of the National Institute for the Blind in this connection should be encouraged. They are also of opinion that the Central Authority should consider the desirability of assisting establishments engaged in the production of books for the blind.

The Poor Law. - The Committee have paid special attention to the position of the blind under the Poor Law, and point out that if proper workshop accommodation is forthcoming, a number of blind 
persons who are at present a charge upon the rates should become partially self-supporting. They recommend that children under 16 should be dealt with by the Local Education Authority of their district, and that there should be no differentiation between children in receipt of out-relief and those in a workhouse. With regard to the treatment of the blind generally under the, Poor Law, the Committee think that so far as possible they should be granted outrelief or receive special accommodation in the Institutions. They consider that blind persons who lose their sight in later life and may have recourse to Poor Law assistance while being trained, should not be disfranchised for this reason; indeed the whole question of disfranchisement of the Blind and of those upon whom the blind are dependent, should be sympathetically considered.

Pensions. - The Committee are satisfied that the sum at present available for pensions is wholly inadequate. They have ascertained from the information furnished to the Committee that the distribution of pensions throughout various parts of the United Kingdom is by no means equal, and that the organization for this purpose is faulty. They recommend that the Central Authority should have further grants placed at its disposal for pensions, having regard especially to the need of provision for the aged and incapable blind. The Central Authority should evolve schemes by which the grants at its disposal for pensions should be co-ordinated with pensions from other sources. In this respect they think that wider powers should be conferred on the Charity Commission in regard to vested funds and funds collected from voluntary subscriptions, and that endeavours should be made to group all the smaller Pension Societies with the larger so as to reduce the sources of distribution and consequent administrative expenditure. The amount of each pension should be increased to a substantial sum; small doles are undesirable. The distribution of pensions over various parts of the United Kingdom should be so arranged as to secure equal facilities for application. At present the out-lying areas appear to receive far less than those near London.

Blinded Soldiers and Sailors.--The Committee are satisfied that these men are adequately provided for at St. Dunstan's Hostel and that active measures are taken by the National Institute for the Blind to secure their future welfare. The Committee feel that the steps taken to ensure the welfare of those blinded in the war merit the greatest approbation.

In conclusion, the Committee speak hopefully of the problem of dealing with the blind. "A great nation ought, undoubtedly, to direct a portion of its resources towards the adoption of wise measures for the relief of the weak and suffering members amongst its citizens. In years to come it should be part of Great Britain's pride that in these Islands can be studied the best methods for the 
prevention of blindness and the best treatment of those whose blindness cannot by any human knowledge or resource be averted."

In answer to a question asked by Mr. Acland Allen in the House of Commons on November 19, 1917, Mr. Hayes Fisher stated that the War Cabinet had decided to authorize the setting up of special departments in the Local Government Board and in the Local Government Board for Scotland respectively, and a separate advisory committee for Scotland. An advisory committee for England and Wales has already been appointed, and is mentioned on p. 45 of the present issue.-EDITOR.

The War Office and the Ophthalmological Society

Report of the Committee appointed by the Council of the Ophthalmological Society to consider

"THE STANDARDS OF VISION DESIRABLE FOR THE PERFORMANCE OF DIFFERENT DUTIES IN THE BRITISH ARMY."*

UP to the present war the British Expeditionary Force had to be prepared to go anywhere in the world and to be independent of . glasses.

The question of wearing spectacles by men in the army had not been taken into account; there had been no regulation in regard to "glasses making a man fit," with the following results :-

1. The standard of vision in the British Army has been low, lower than in the Continental armies.

2. Many men in the past have been refused for their sight who would have made useful soldiers if they had been allowed to wear glasses.

3. Those enlisted have not been made as efficient as they might have been.

In the Continental armies, where glasses are allowed, the standard of acuity of vision required was $6 / 12$ with or without glasses, as opposed to 6/24 unaided in the British Army.

Now that the British Army, as the result of the war, has had to be greatly increased, men who require glasses have had to be enlisted, and glasses are being issued to those who need them. The visual standard for general service (Class A) adopted early this year, in which visual acuity with glasses is taken into consideration for the first time, is as follows :-

*This Report will be presented at the next-meeting of the Society in May, 1918, and will then be open to discussion. 